\title{
Eosinophils, basophils and type 2 immune microenvironments in COPD-affected lung tissue
}

\author{
Prajakta Jogdand ${ }^{1}$, Premkumar Siddhuraj ${ }^{1}$, Michiko Mori ${ }^{1}$, Caroline Sanden ${ }^{1,2}$, \\ Jimmie Jönsson ${ }^{2}$, Andrew F. Walls ${ }^{3}$, Jennifer Kearley ${ }^{4}$, Alison A. Humbles ${ }^{4}$, \\ Roland Kolbeck ${ }^{4}$, Leif Bjermer ${ }^{5}$, Paul Newbold ${ }^{6}$ and Jonas S. Erjefältt ${ }^{1,5}$ \\ Affiliations: ${ }^{1}$ Dept of Experimental Medical Science, Lund University, Lund, Sweden. ${ }^{2}$ Medetect AB, Lund, \\ Sweden. ${ }^{3}$ Clinical and Experimental Sciences, University of Southampton, Southampton General Hospital, \\ Southampton, UK. ${ }^{4}$ Dept of Respiratory, Inflammation and Autoimmunity, AstraZeneca, Gaithersburg. MD, \\ USA. ${ }^{5}$ Dept of Respiratory Medicine and Allergology, Lund University, Lund, Sweden. ${ }^{6}$ Dept of Translational \\ Sciences, AstraZeneca, Gaithersburg, MD, USA.
}

Correspondence: Jonas S. Erjefält, Unit of Airway Inflammation, BMC D12, Lund University, SE-221 84, Lund, Sweden. E-mail: jonas.erjefaltamed.lu.se

@ERSpublications

Highly localised Th2- and eosinophil-rich pockets were identified in COPD-affected lungs, which increased in number with increasing disease severity and included basophils. This exemplifies a novel type of heterogeneity in the immunopathology of COPD. http://bit.ly/2HexTco

Cite this article as: Jogdand $\mathrm{P}$, Siddhuraj P, Mori M, et al. Eosinophils, basophils and type 2 immune microenvironments in COPD-affected lung tissue. Eur Respir J 2020; 55: 1900110 [https://doi.org/10.1183/ 13993003.00110-2019].

ABSTRACT Although elevated blood or sputum eosinophils are present in many patients with COPD, uncertainties remain regarding the anatomical distribution pattern of lung-infiltrating eosinophils. Basophils have remained virtually unexplored in COPD. This study mapped tissue-infiltrating eosinophils, basophils and eosinophil-promoting immune mechanisms in COPD-affected lungs.

Surgical lung tissue and biopsies from major anatomical compartments were obtained from COPD patients with severity grades Global Initiative for Chronic Obstructive Lung Disease stages I-IV; neversmokers/smokers served as controls. Automated immunohistochemistry and in situ hybridisation identified immune cells, the type 2 immunity marker GATA3 and eotaxins (CCL11, CCL24).

Eosinophils and basophils were present in all anatomical compartments of COPD-affected lungs and increased significantly in very severe COPD. The eosinophilia was strikingly patchy, and focal eosinophilrich microenvironments were spatially linked with GATA $^{+}$cells, including type 2 helper T-cell lymphocytes and type 2 innate lymphoid cells. A similarly localised and interleukin-33/ST2-dependent eosinophilia was demonstrated in influenza-infected mice. Both mice and patients displayed spatially confined eotaxin signatures with $\mathrm{CCL} 11^{+}$fibroblasts and CCL $24^{+}$macrophages.

In addition to identifying tissue basophilia as a novel feature of advanced COPD, the identification of spatially confined eosinophil-rich type 2 microenvironments represents a novel type of heterogeneity in the immunopathology of COPD that is likely to have implications for personalised treatment.

This article has supplementary material available from erj.ersjournals.com

Received: 15 Jan 2019 | Accepted after revision: 6 Feb 2020

Copyright OERS 2020. This version is distributed under the terms of the Creative Commons Attribution NonCommercial Licence 4.0. 


\section{Introduction}

COPD impacts on global morbidity and mortality [1]. Underlying the disease is chronic inflammation leading to bronchitis, bronchiolitis and emphysema resulting from long-term exposure to inhaled irritants (e.g. tobacco smoke) [2, 3]. COPD pathology has traditionally been attributed to innate immune mechanisms [3], but adaptive immune mechanisms are also activated [4,5]. The immunopathology is further complicated by a marked heterogeneity in granulocyte profiles, with an increased attention to eosinophil signatures in COPD [6,7]. Several studies have demonstrated high blood and/or sputum eosinophil counts in a significant percentage of patients with COPD [6-8]. Cluster analysis of sputum granulocyte profiles has proposed eosinophil-rich sputum eosinophilia as a sign of a distinct eosinophil COPD phenotype [9].

Type 2 cytokines, particularly interleukin (IL)-5, are crucial for eosinophil development, maturation and tissue longevity $[10,11]$. This IL-5 dependence has been the rationale for targeting eosinophil-high COPD with neutralising anti-IL-5 (mepolizumab) and anti-IL-5 receptor- $\alpha$ (IL-5R $\alpha$; benralizumab) antibodies $[12,13]$. Basophils also express IL-5R $\alpha$ and are affected by IL-5/IL-5R $\alpha$ blockade [14]. However, limited data exist on the tissue infiltration pattern and density of basophils in COPD-affected lungs.

Lung tissue-infiltrating eosinophils in COPD remain largely unexplored. Previous studies have confirmed eosinophil presence in central and distal compartments $[15,16]$. However, important questions remain about the anatomical localisation and infiltration patterns and the theoretical underpinning for eosinophilia in COPD and its immunological triggers. Although type 2 cytokines are classically derived from antigen-activated $\mathrm{CD}^{+}$type 2 helper T-cell (Th2) lymphocytes, eosinophilia may develop through activated type 2 innate lymphoid cells (ILC2) [17-19], which upon activation (e.g. by IL-33) can rapidly mount a transient type 2 response $[17,18]$. However, it remains to be demonstrated if ILC2 cells are present in tissues with eosinophilia in COPD-affected lungs. Eosinophil chemoattractant molecules in COPD also require investigation.

The aim of this study was to perform holistic spatial mapping of tissue-infiltrating eosinophils in COPD-affected lungs at different disease stages, and to identify key immunological mechanisms thought to promote tissue eosinophilia. The investigation involved key anatomical lung regions, including the poorly studied distal lung areas. In addition, we performed the first systematic quantification of tissue-infiltrating basophils in COPD-affected lungs. Finally, using an experimental model, we explored respiratory viral infections as a potential trigger of transient and patchy eosinophilia.

\section{Materials and methods}

Materials and methods are summarised here; further detailed procedures are provided in the supplementary material.

\section{Samples from participants}

For the main study, surgical tissues were collected from 57 patients at Skåne University Hospital (Lund, Sweden), and processed for histological analysis. Lung resection samples were obtained from patients with mild to severe COPD (Global Initiative for Chronic Obstructive Lung Disease (GOLD) stages I-III) and controls (never-smokers/smokers) undergoing surgery for delineated tumours). For patients with very severe (GOLD IV) COPD, lung tissue was obtained from explanted lungs after transplantation surgery. Patient demographics are presented in table 1. mRNA-preserved tissues for in situ hybridisation (ISH) were collected from bronchial biopsies from 30 additional patients (supplementary table E2). Tissue processing protocols were identical for all patient groups. All clinical procedures were approved by the local Swedish research ethics committee in Lund, Sweden. All participants signed informed consent forms.

\section{Immunohistochemistry}

After antigen retrieval (PT-Link; DakoCytomation, Glostrup, Denmark), tissue sections were subjected to automated double and triple immunostaining (Autostainer Plus; DakoCytomation). The main analysis used a triple immunohistochemistry (IHC) protocol to simultaneously detect eosinophils, basophils, and the Th2 surrogate marker GATA3. Th2 lymphocytes were identified as GATA3 ${ }^{+}, \mathrm{CD}^{+}{ }^{+}$cells. ILC2 cells were identified as lineage-negative, $\mathrm{CD} 25^{+}, \mathrm{GATA}^{+}$cells after confounding non-ILC2 cells were physically blocked by prior chromogenic staining and denaturating blocking, as described previously [20]. In addition, various standard IHC cell markers were used for general immune cell exploration and for identification of chemokine-expressing cells. All antibodies had been extensively validated for use in clinical diagnosis or research (supplementary table E1).

\section{In-situ hybridisation}

Human and mouse eotaxin-1 (CCL11) and eotaxin-2 (CCL24) mRNA were visualised using the RNAscope 2.5 assay kit (Advanced Cell Diagnostics, Hayward, CA, USA). Sections were incubated with 
TABLE 1 Patient demographics

\begin{tabular}{|c|c|c|c|c|c|c|}
\hline & \multirow[t]{2}{*}{ Never-smokers } & \multirow{2}{*}{$\begin{array}{c}\text { Smokers } \\
\text { without COPD }\end{array}$} & \multicolumn{3}{|c|}{ COPD } & \multirow{2}{*}{$\begin{array}{l}\text { Overall } \\
\text { p-value }\end{array}$} \\
\hline & & & GOLD stage I & GOLD stage II-III & GOLD stage IV & \\
\hline Male/female ${ }^{\pi}$ & $2 / 6^{91}$ & $3 / 6^{\text {ๆ }}$ & $4 / 3^{9}$ & $13 / 5^{\uparrow}$ & $5 / 10^{\text {ๆ }}$ & \\
\hline Age years & $66(33-76)$ & $58(47-68)$ & $69(56-75)$ & $70(53-75)^{f}$ & $62(53-66)^{\# \#}$ & 0.015 \\
\hline Height m & $1.6(1.5-1.8)$ & $1.7(1.6-1.8)$ & $1.7(1.6-1.8)$ & $1.7(1.5-1.9)$ & $1.7(1.5-1.9)$ & 0.276 \\
\hline $\begin{array}{l}\text { Smoking status ex-smoker/ } \\
\text { current smoker }\end{array}$ & NA & $5 / 4$ & $3 / 4$ & $12 / 5^{+}$ & $15 / 0$ & \\
\hline $\mathrm{FEV}_{1} \mathrm{~L}$ & $2.5(1.7-5.1)$ & $2.67(1.8-3.5)$ & $2.8(1.6-3.2)$ & $1.9(1.1-2.9)$ & 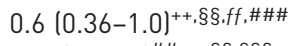 & $<0.0001$ \\
\hline $\mathrm{FEV}_{1} / \mathrm{FVC} \%$ & $81.5(66-121)$ & 76 (71-88) & $66.5(65-70)$ & 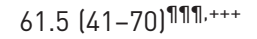 & 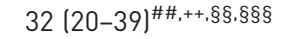 & $<0.0001$ \\
\hline $\mathrm{FEV}_{1} \%$ predicted & $108(82-141)$ & $95(75-120)$ & $86.66(80-95)$ & $69(43.2-77.8)^{\text {กा, ,++ }}$ & $23.84(15-28)^{\# \#,++, \S \S . f f}$ & $<0.0001$ \\
\hline \multicolumn{7}{|l|}{ Inhaled $\beta_{2}$-agonists } \\
\hline Long-acting yes/no/unknown & $0 / 8 / 0$ & $0 / 9 / 0$ & $0 / 7 / 0$ & $2 / 13 / 3$ & $10 / 4 / 1^{\S}$ & \\
\hline $\begin{array}{l}\text { Inhaled short-acting } \boldsymbol{\beta}_{2} \text {-agonist } \\
\text { plus anticholinergics } \\
\text { yes/no/unknown }\end{array}$ & $0 / 8 / 0$ & $0 / 9 / 0$ & $0 / 7 / 0$ & $1 / 14 / 3$ & $3 / 11 / 1^{\S}$ & \\
\hline \multicolumn{7}{|l|}{ Corticosteroids } \\
\hline Inhaled yes/no/unknown & $0 / 8 / 0$ & $0 / 9 / 0$ & $0 / 7 / 0$ & $2 / 13 / 3$ & $2 / 12 / 1^{\S}$ & \\
\hline Oral yes/no/unknown & $0 / 8 / 0$ & $0 / 9 / 0$ & $0 / 7 / 0$ & $0 / 15 / 3$ & $2 / 12 / 1^{\S}$ & \\
\hline $\begin{array}{l}\text { Inhaled long-acting } \boldsymbol{\beta}_{2} \text {-agonist } \\
\text { plus corticosteroids } \\
\text { yes/no/unknown }\end{array}$ & $0 / 8 / 0$ & $0 / 9 / 0$ & $0 / 7 / 0$ & $2 / 13 / 3$ & $9 / 4 / 2^{\S}$ & \\
\hline Mucolytics yes/no/unknown & $0 / 8 / 0$ & $0 / 9 / 0$ & $2 / 5 / 0$ & $0 / 15 / 3$ & $7 / 6 / 2^{\S}$ & \\
\hline
\end{tabular}

Data are presented as median (range) or $\mathrm{n}$. Statistical analysis was performed using Kruskal-Wallis nonparametric test followed by Dunn's multiple comparison post-test. Further patient descriptions, including inclusion and exclusion criteria are presented in the supplementary material. GOLD: Global Initiative for Chronic Obstructive Lung Disease; BMI: body mass index; FEV 1 : forced expiratory volume in 1 s; FVC: forced vital capacity; NA: not applicable. " : two patients with GOLD stage III COPD (median (range) FEV 144.5 (43.2-45.9)\% predicted); ": the mean age of the study group was 64 years; ${ }^{+}$: data missing from one patient; ${ }^{\S}$ : one patient with unknown medical history; ${ }^{f}$ : $<<0.01$ versus smokers without

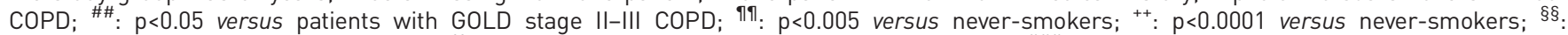
$\mathrm{p}<0.0001$ versus smokers without COPD; ${ }^{f f}: \mathrm{p}<0.0005$ versus patients with GOLD stage I COPD; ${ }^{\# \# \#}$ : $p<0.005$ versus patients with GOLD stage II-III COPD; กाก: $p<0.01$ versus never-smokers; ${ }^{+++}: p<0.05$ versus smokers without COPD; ${ }^{\S \S}: p<0.02$ versus patients with GOLD stage I COPD.

endogenous enzyme block, boiled in pretreatment buffer and treated with protease prior to target probe hybridisation (CCL11, CCL24). Target RNA was amplified and visualised with coloured chromogen.

\section{Quantitative IHC and computerised image analysis}

All whole IHC- and ISH-stained sections were digitised using a ScanScope Slide Scanner (Aperio Technologies, Vista, CA, USA). High-resolution images were subjected to computerised analysis, and the immunoreactivity/detection chromogens were colour segmented, quantified and normalised to the analysed tissue area (Visiomorph; Visiopharm, Hørsholm, Denmark). For each patient in the main study, several large sections containing bronchioles, bronchi (GOLD IV only), pulmonary vessels and alveolar parenchyma were analysed, representing two to three separated lung regions. $\mathrm{X}, \mathrm{Y}$ coordinates from computer-segmented individual cells were analysed by methods for spatial distribution and cell clustering (point pattern analysis) and accumulation of GATA3 cells within defined eosinophil microenvironments (neighbour analysis, Cell Community Viewer, CCV 1.22; Medetect, Lund, Sweden, and Monte Carlo simulation; supplementary figure E1).

\section{Model of viral exacerbation with and without prior smoke exposure}

Archive lung mouse tissues [21,22] were used to investigate potential eosinophil chemotaxis responses and formation of patchy eosinophilia in wild-type or IL-33-deficient mice terminated 6 days after exposure to virus (mouse-adapted H1N1 influenza A; A/FM/1/47-MA) with or without 11 days of prior daily 
tobacco smoke exposure. These studies were approved by AstraZeneca's institutional animal care and use committee.

\section{Statistical analysis}

Data were analysed in GraphPad Prism (GraphPad Software, San Diego, CA, USA). The nonparametric Kruskal-Wallis test detected overall differences between patient groups, and Dunn's test evaluated post hoc between-group comparisons conservatively. The Spearman rank (rs) correlation test detected significant correlations between groups. Spatial interaction and bivariate point pattern analysis were performed by computerised point pattern generation and circular neighbourhood analysis (CCV; Medetect) and by Monte Carlo simulation tests (ImageJ v1.51S, National Institutes of Health, Bethesda, MD, USA) and the MOSAIC Interaction Analysis Plugin. For mouse experiments, an unpaired t-test detected differences between virus-infected mouse groups. Pearson parametric correlation and linear regression determined eotaxin mRNA correlation with tissue virus content.

\section{Results}

Additional results are presented in the supplementary material (table E2, figures E1-E4).

\section{Samples from participants}

The main surgical tissue study included patients with COPD and controls $(n=57)$. Demographics and clinical characteristics are presented in table 1 and supplementary table E2.

\section{Tissue infiltration of eosinophils and basophils in COPD occurs across all major anatomical lung} regions

Conducting airways

IHC revealed scattered bronchial eosinophils and basophils in most patients. However, more dense eosinophilia was present only in a subset of the patients and statistically increased densities compared to controls or milder disease was only found in advanced-stage (GOLD IV) COPD (figures 1 and 2). Basophil counts, although smaller than for eosinophils, were significantly increased in advanced-stage COPD (figure 1). Intriguingly, epithelial basophils were virtually absent in controls and mild disease, had a tendency towards increase in GOLD II-III and were markedly upregulated in GOLD IV patients. Similarly, densities of the type 2 surrogate marker GATA3 were increased in advanced disease (figure 1c). Bronchi (large airways) displayed similar high eosinophil, basophil and GATA3 concentrations as bronchioles from the same GOLD IV patients (supplementary figure E2c). In the biopsy cohorts, both eosinophils and basophils were statistically increased in pooled GOLD I-III patients compared to never-smokers, but not smoking controls (supplementary figure E2a and b).

\section{Distal lung compartments}

Most patients had detectable eosinophil concentrations in the peripheral lung tissue including the alveolar parenchyma and distal lymphoid tissue. Statistically elevated eosinophil concentrations were observed in GOLD stage IV (figure 3). Particularly high counts of eosinophils were associated with ectopic lymphoid follicles (an immunopathological hallmark of COPD; figures $2 \mathrm{~b}$ and $3 \mathrm{a}$ ) that were also rich in GATA ${ }^{+}$ cells (figure 3c). Eosinophil counts were greater, but basophils displayed a similar magnitude of relative increased density in distal lung compartments compared with non-COPD controls (figures 2 and 3).

\section{Tissue eosinophilia and basophil infiltration are spatially linked}

A significant statistical correlation was found between eosinophil and basophil densities within the same tissue environments, represented here by the $2-4-\mathrm{cm}^{2}$ surgical resection blocks. This correlation was present in both central airways (bronchi) and distal lung compartments, such as small airways (bronchioles), the total peripheral lung tissue and the alveolar parenchyma (figure 4).

\section{Accumulation of tissue-infiltrating eosinophils in COPD is patchy and concentrated in spatially distinct Th2 microenvironments \\ Distinct eosinophil and basophil microenvironments in COPD lungs}

We observed marked patchiness of the eosinophil distribution at a microenvironmental level (figure 5). Eosinophils within a typical lung tissue section were commonly restricted to distinct focal microenvironments (eosinophil pockets; figure 5a and c, supplementary figures E1 and E3). Enumeration of eosinophil and basophil clusters and their content of $\mathrm{GATA}^{+}$in distal lung blocks revealed a marked cluster increase in GOLD IV COPD (figure 5d). Spatial eosinophil and basophil clusters were found in all anatomical lung regions, the most distinct examples being in the lamina propria region in bronchi and bronchioles (small airways; where neighbour analysis confirmed a statistically secured clustering, $\mathrm{p}<0.001$ ). 
Total bronchiolar wall

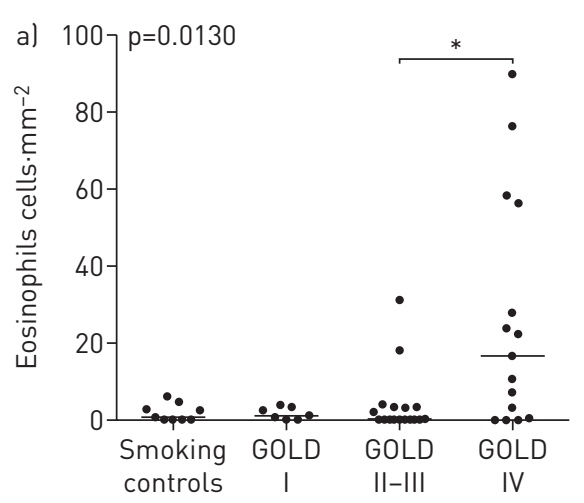

Epithelium
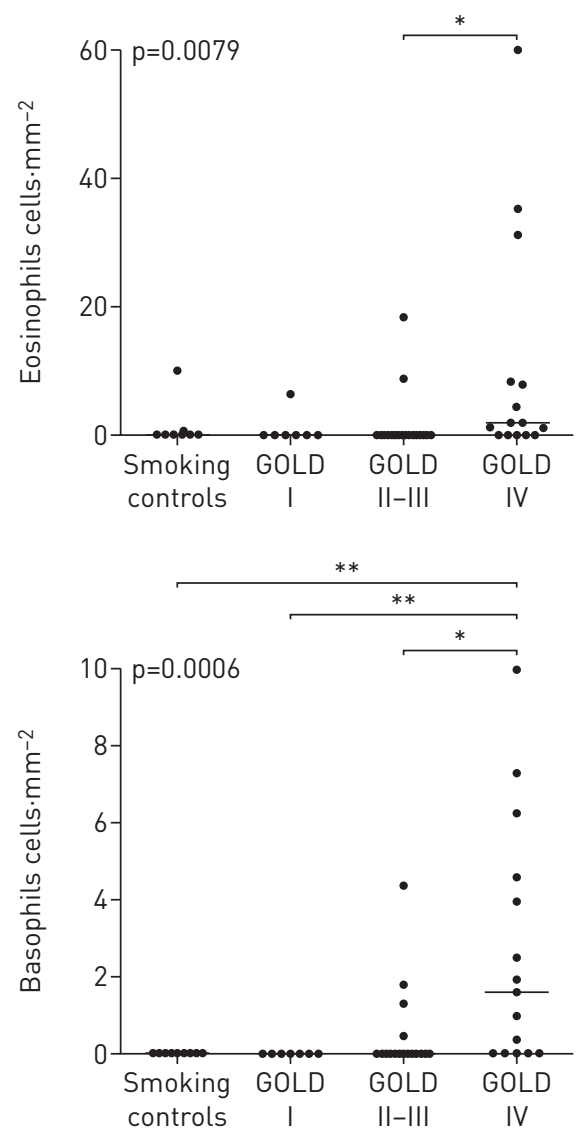

b) 50 -1
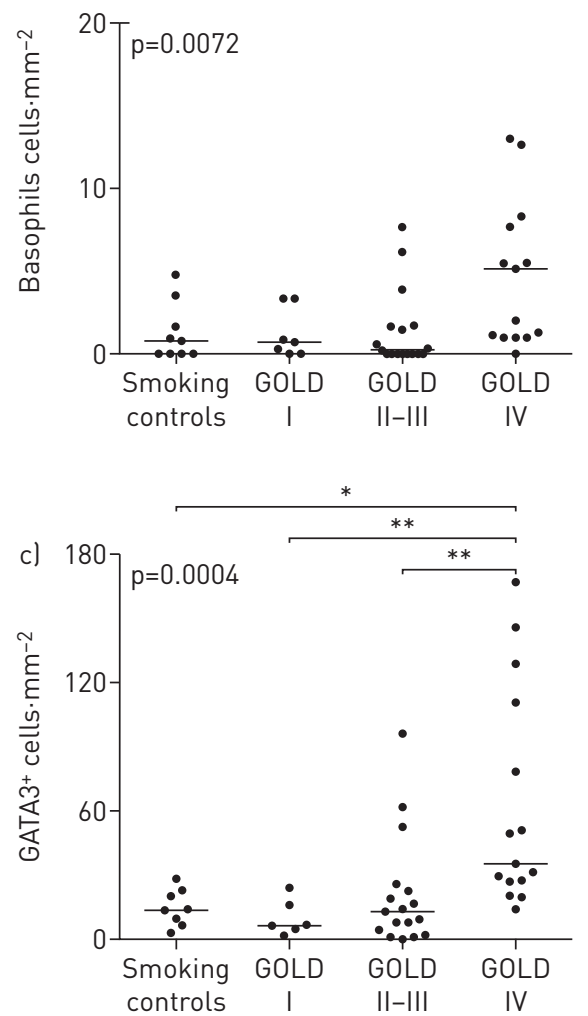

Subepithelial tissue

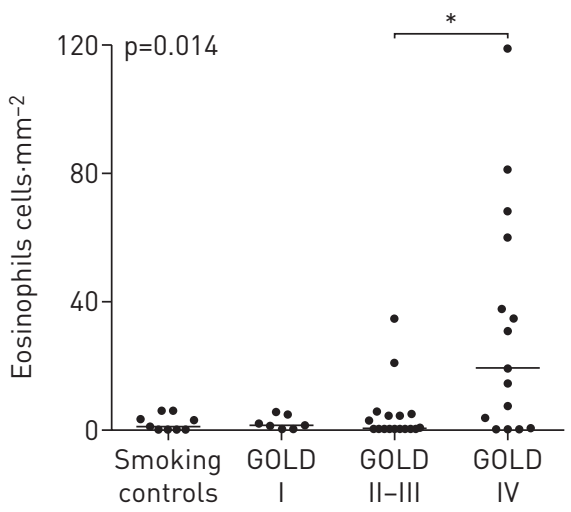

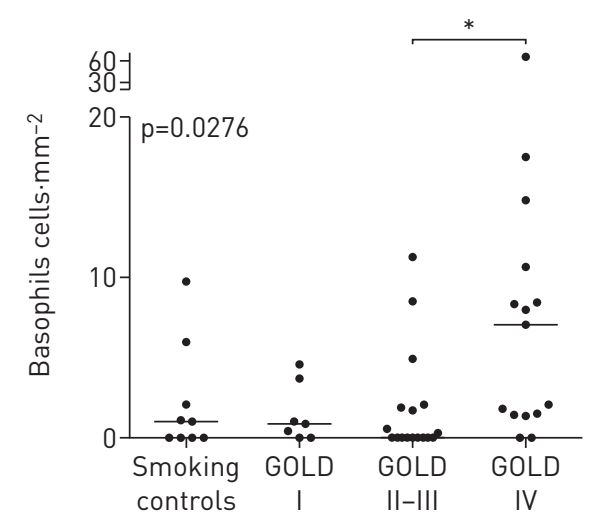

FIGURE 1 Scattergrams showing densities of tissue-infiltrating a) eosinophils and b) basophils and c) the surrogate type 2 immune marker GATA3 in the total wall, epithelial and subepithelial compartments of bronchioles (small airways) in patients with Global Initiative for Chronic Obstructive Lung Disease (GOLD) I-IV COPD and matching controls. Data are presented as patient mean densities and group median values. p-values quoted in the figure represent overall statistical difference between patients with COPD and controls, as determined by a nonparametric Kruskal-Wallis one-way ANOVA with Dunn's multiple comparison post hoc test (mean rank of each subgroup is compared to every other subgroup). *: $p<0.05$, ${ }^{* *}: \mathrm{p}<0.01$.

Eosinophil microenvironment is linked to a localised GATA3 signature

Repeated staining further revealed that the presence of distinct eosinophil-rich microenvironments was accompanied by focal gathering of basophils and $\mathrm{GATA}^{+}$cells (figure 5a and c). A spatial statistics analysis approach was used to quantify the density of $\mathrm{GATA}^{+}$cells inside and outside the eosinophil microenvironments (supplementary figure E1). For lung samples with patchy eosinophilia, the density and clustering of $\mathrm{GATA}^{+}$cells were significantly and several-fold greater in eosinophil neighbourhood microenvironments compared with non-neighbourhood regions (figure 5b). A spatial GATA3-eosinophil relationship was confirmed by point pattern Monte Carlo simulations $(\mathrm{p}<0.001)$. 

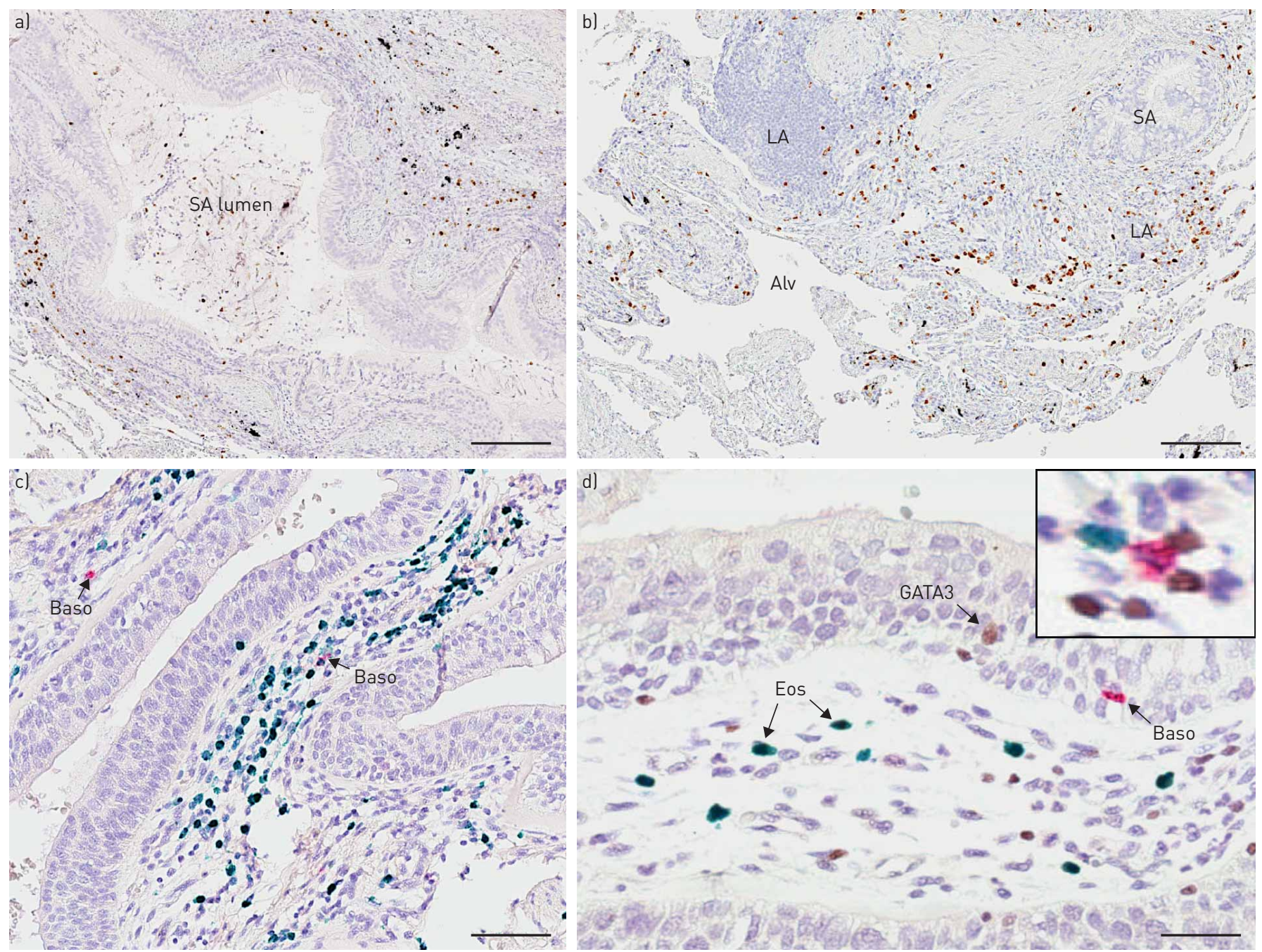

FIGURE 2 Bright-field micrographs exemplifying eosinophil, basophil and GATA3 staining in patients with COPD representative of an eosinophil-high profile. $a$ and b) Single eosinophil staining (brown EG2 immunoreactivity); c) double immunohistochemistry (IHC) lung section stained for basophils (red, alkaline phosphatase) and eosinophils (vina green). d) Triple IHC staining for eosinophils (vina green), basophils (red, alkaline phosphatase) and GATA3 (brown diaminobenzidine; inset in d exemplifies greater magnification of triple-stained section and brown $\mathrm{GATA}^{+}$cells amid green $\mathrm{EG}^{+}$eosinophils and a red BB1 ${ }^{+}$basophil). Arrows indicate positive cells. SA: small airway; LA: lymphoid aggregate; Alv: alveolar parenchyma; Baso: basophil; Eos: eosinophil. Scale bars a) $100 \mu \mathrm{m}$, b) $120 \mu \mathrm{m}$, c) $85 \mu \mathrm{m}$, d) $50 \mu \mathrm{m}$.

Presence of ILC2 and Th2 lymphocytes in eosinophil microenvironments

ILC2 cells could represent a local type 2 cytokine source, promoting the present type of localised eosinophilia. Our unique ILC2 staining protocol showed clear localisation of ILC2 cells within eosinophil foci (figure 6a). As expected, ILC2 counts were significantly lower than for classic $\mathrm{CD}^{+} \mathrm{Th} 2$ lymphocytes with the ILC2 fraction of the sum of ILC2 and Th2 cells in eosinophil-rich patients being mean \pm SD 3.5 $\pm 3.8 \%$. Notably, the fraction of ILC2 cells in the airway epithelium was $15.5 \pm 18 \%$ of the sum of ILC2 and Th2 cells.

\section{Exploration of respiratory viral infections as a potential cause of patchy and spatially distinct} eosinophil accumulation in lung tissues

Our results, from exploration of eosinophil responses in lung tissues from a validated mouse exacerbation model with smoke and/or influenza infection, demonstrate that viral infection causes a robust infiltration of eosinophils (figure $7 \mathrm{a}$ and supplementary figure E4d). The generated eosinophilia was patchy and colocalised to the patchy infection (influenza presence) described in the present model (figure 7) [21]. Mice exposed to prior tobacco smoke did not mount a similar eosinophil response upon infection (figure 7). The development of influenza-induced eosinophilia seems to involve mediators of the IL-33/ST2 axis, as virus-induced

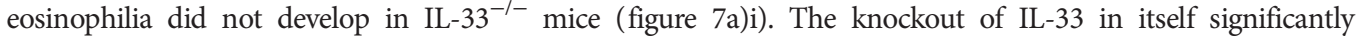
reduced the low-grade baseline presence of eosinophils in noninfected wild-type mice (figure 7a)ii). 
Total peripheral lung tissue
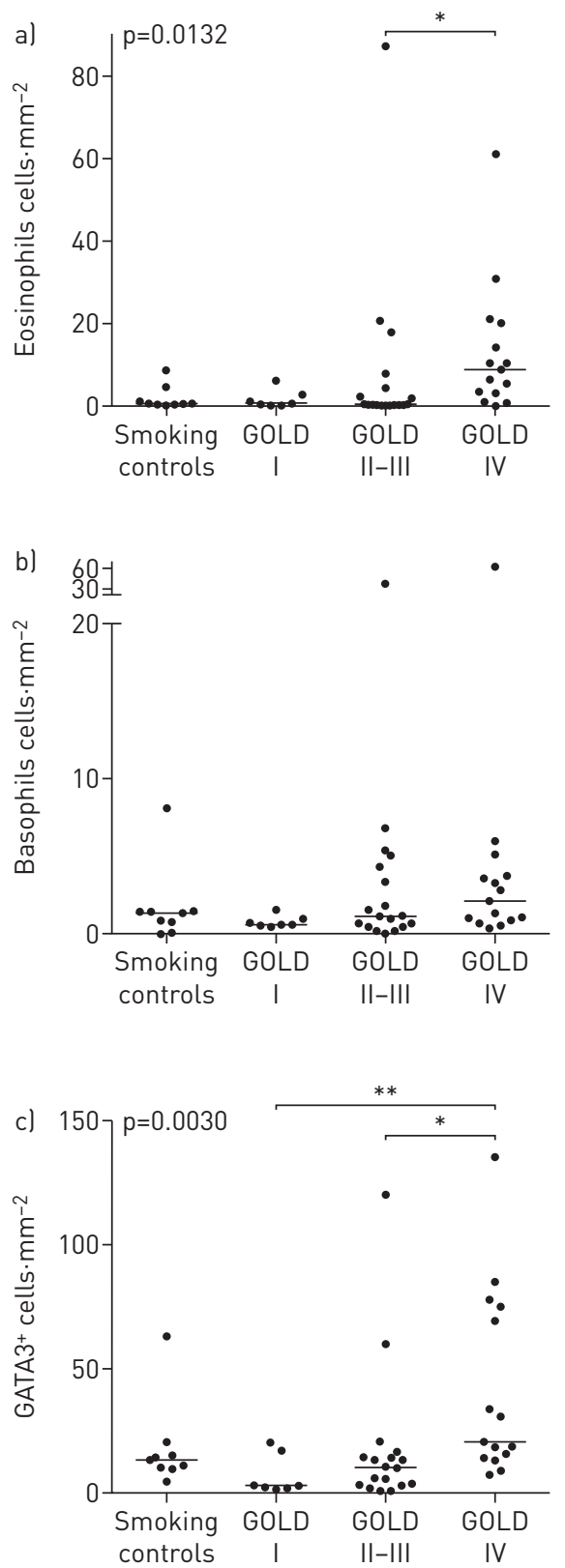

Alveolar

parenchyma
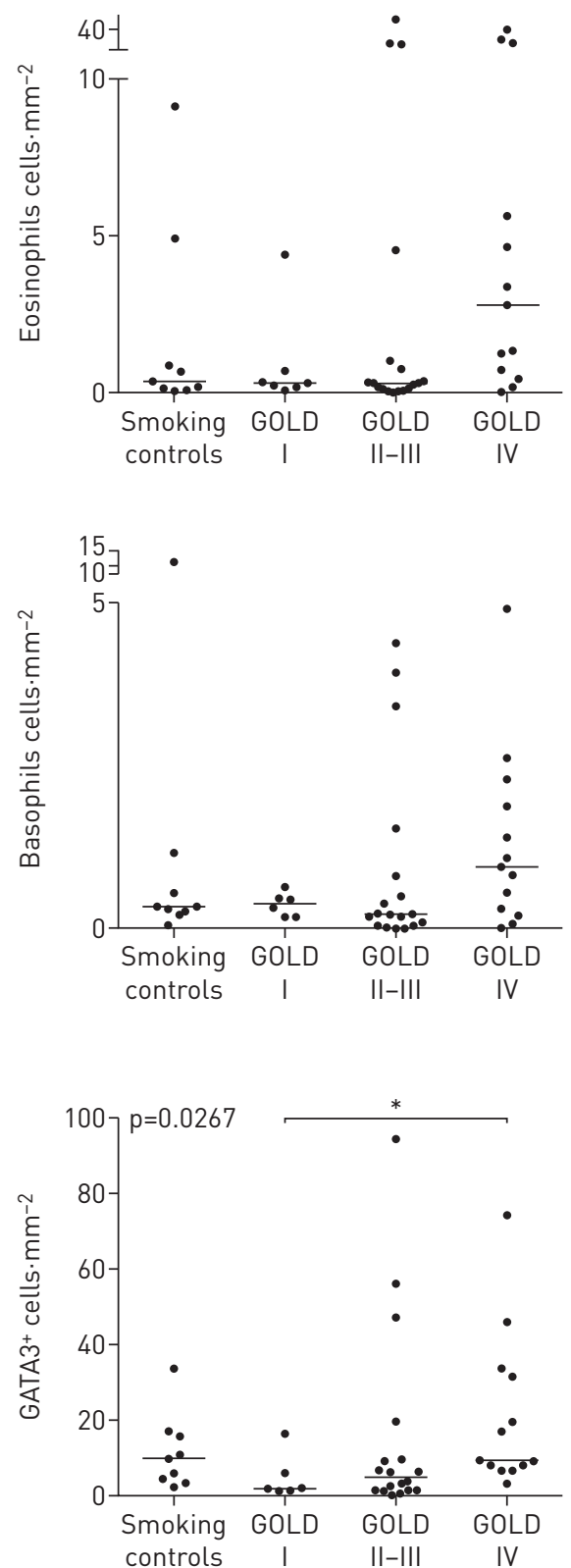
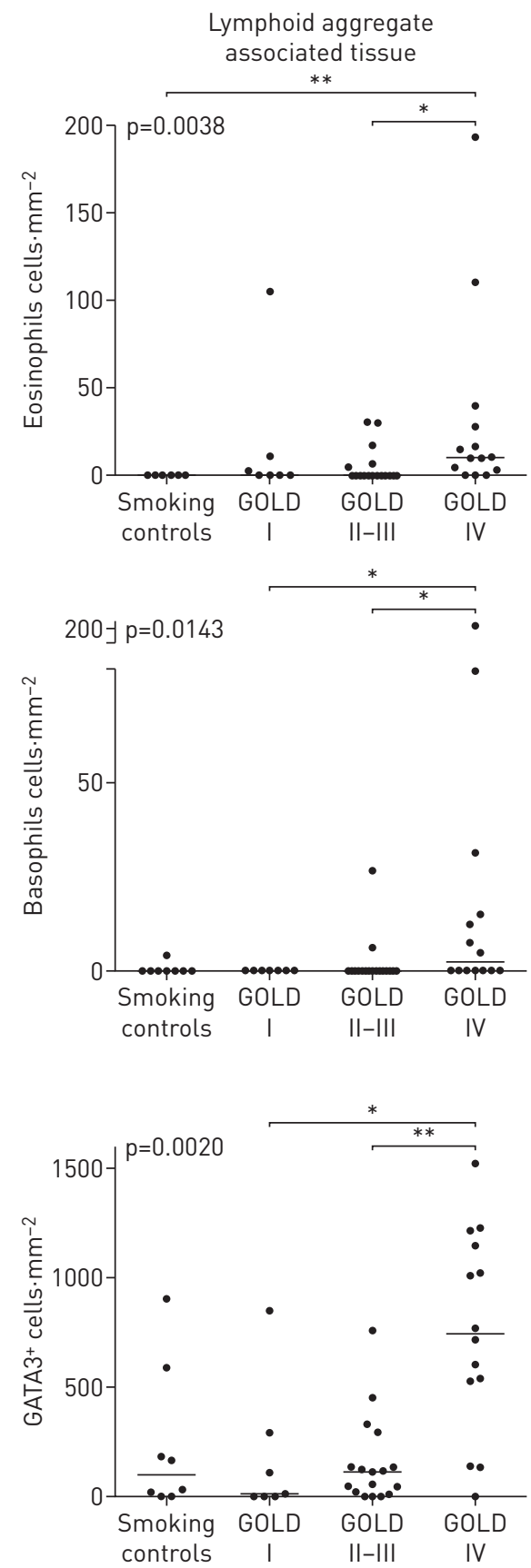

FIGURE 3 Scattergrams of densities of tissue-infiltrating a) eosinophils and b) basophils and c) the surrogate type 2 helper T-cell marker GATA3 in distal lung compartments, here divided into total peripheral lung tissue (i.e. lung tissue in which any large conducting airways and large pulmonary vessels have been excluded), alveolar parenchyma (with small airways and large to mid-sized vessels and lymphoid tissue excluded) and lymphoid-associated tissue. Data are presented as patient mean densities and group median values. p-values represent overall statistical difference between patients with COPD and controls, as determined by a nonparametric Kruskal-Wallis one-way ANOVA with Dunn's multiple comparison post hoc test (mean rank of each subgroup is compared to every other subgroup). GOLD: Global Initiative for Chronic Obstructive Lung Disease. ${ }^{*}: p<0.05,{ }^{* *}: p<0.01$.

COPD-affected lungs and virus-infected mice display localised expression of eotaxins

Eotaxins are key chemoattractants for the migration and tissue homing of eosinophils. Combined ISH+IHC was used to reveal the presence and identity of eotaxin-expressing cells in patients with COPD and virus-infected mice. Virus infection in mice elicited strong and significant upregulation of both total lung CCL11 and CCL24 (figure 7b). The expression for CCL11 was distinct, restricted to large perivascular structural cells (figure $7 \mathrm{c}$ and $\mathrm{d}$ ) and primarily localised to infected and eosinophil-rich lung areas (figure $7 \mathrm{c}$ and $\mathrm{d}$ ). The distribution of CCL24 was more widespread than CCL11 and foremost localised to alveolar macrophages within infected and eosinophil-rich lung areas (supplementary figure E4c). 

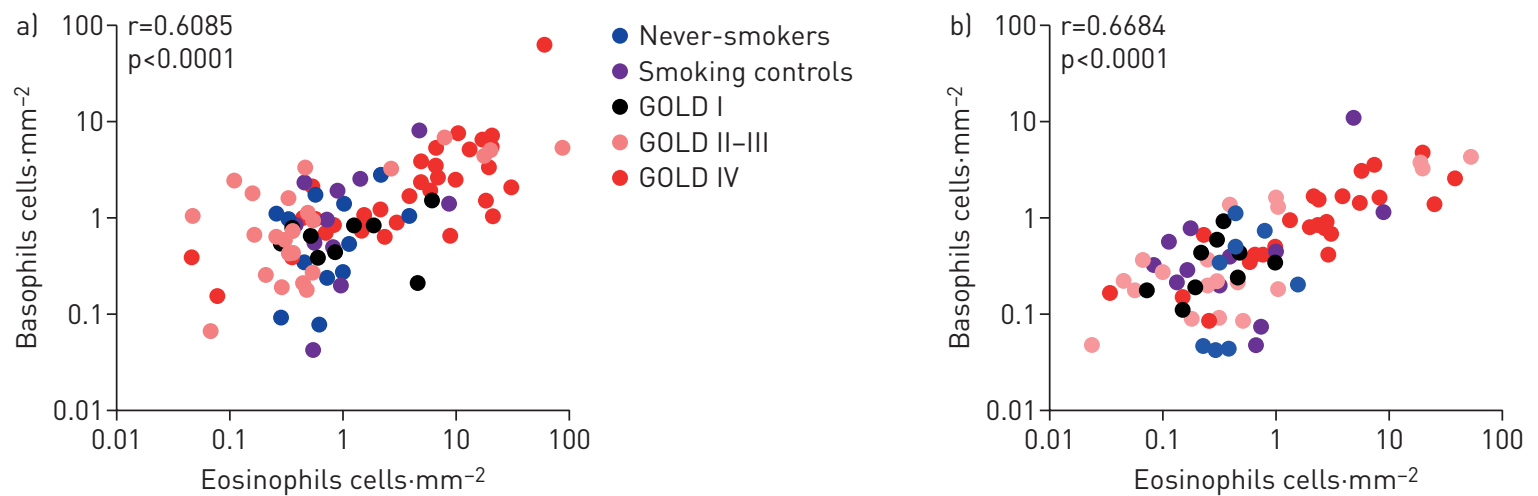

Never-smokers

- Smoking controls

- GOLD I

GOLD II-III

GOLD IV
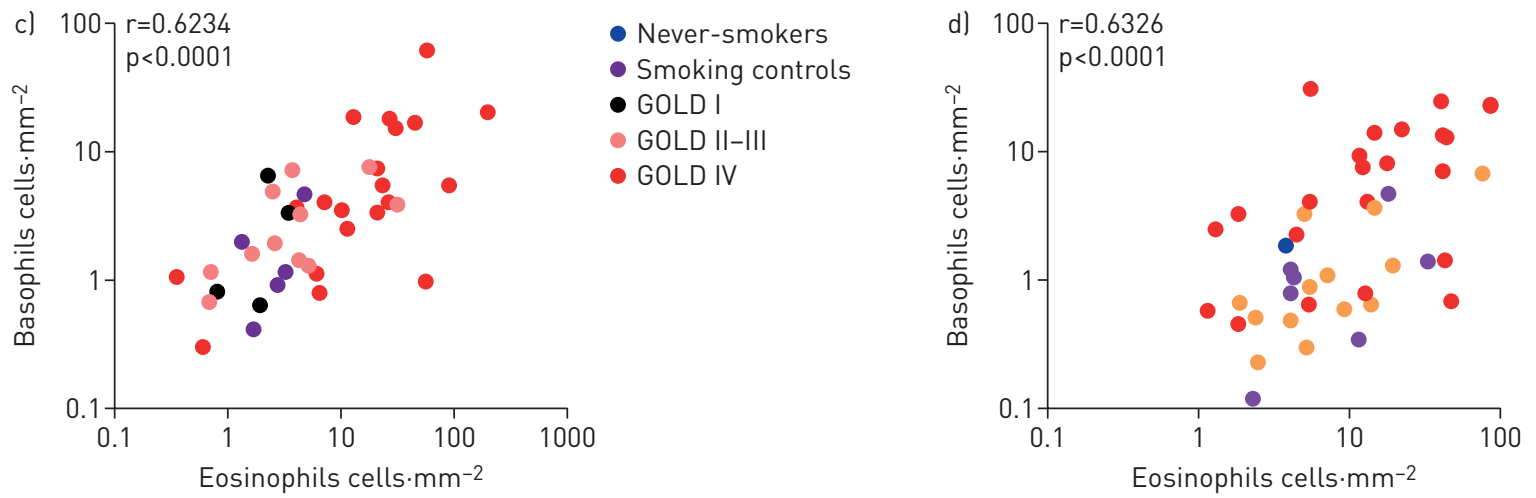

FIGURE 4 Scattergrams showing correlations between eosinophils and basophils in lung compartments a) peripheral tissue; b) alveolar parenchyma; c) small airways; d) bronchi. Data are presented as mean values in individual tissue blocks (i.e. blocks representing distinct and spatially separated anatomical regions within each analysed type of lung compartment). Values were log-transformed to yield better visualisation of the correlation (as a result sections with zero values for any of the cell type are omitted). Whereas a-c represent surgical cases from the main study, d represents pooled mean values from surgical Global Initiative for Chronic Obstructive Lung Disease (GOLD) stage IV COPD samples and endobronchial biopsies from GOLD I-II patients collected to yield mRNA-preserved tissue samples for chemokine mRNA visualisation by in situ hybridisation. Spearman rank correlation test was used to determine the degree of correlation.

In human COPD tissues, CCL11 had a variable and patchy localisation and was expressed by a subset of elongated fibroblast-like (vimentin ${ }^{+}$) structural cells. In contrast to mice, CCL11 in human COPD-affected lungs was localised mainly just under the airway or glandular epithelium (figure 6b), which was also the most prominent site for eosinophil clusters. CCL24-expressing cells were mainly $\mathrm{CD}^{+} 8^{+}$alveolar macrophages (figure 6c) and had no visually apparent colocalisation to eosinophil clusters.

\section{Discussion}

This study reveals several new aspects of eosinophils, basophils and Th2 immunity in COPD, particularly the lack of inflammation uniformity in COPD-affected lungs. The study excluded patients with any atopy or history of allergy. Therefore, the data reveal the nature of COPD-specific eosinophilia and Th2 immunity for the type of eosinophilia currently under intense investigation in COPD and nonallergic asthma phenotypes. Interestingly, eosinophil-high COPD has been demonstrated to display histopathological features normally ascribed to eosinophilic asthma, such as thickening of the reticular layer of the basement membrane [23]. This raises the possibility of shared underlying type 2 mechanisms. Therefore, although we are confident about the diagnosis of COPD in this study, we acknowledge the complexity related to its definition and the differential diagnosis between nonallergic eosinophilic asthma with fixed obstruction, eosinophil-high COPD and asthma-COPD overlap syndrome [24].

The fact that elevated eosinophil and basophil numbers were observed for patients with COPD with very severe disease receiving high-dosage inhaled corticosteroid treatment further supports observations in asthma that nonallergic eosinophilia is more resistant to steroids than classic allergen-induced eosinophilia. In addition, this agrees with reports that alveolar nitric oxide concentration is increased in patients with more advanced COPD, indicating an increased nonallergic type 2 signal in the distal airways [25]. The issue of steroid sensitivity for patients with COPD is complicated by observations of blood or sputum eosinophilia in milder disease being an indicator of increased responsiveness [26, 27]. Notably, in our sub-biopsy study, both eosinophils and basophils were also increased in milder disease. However, 

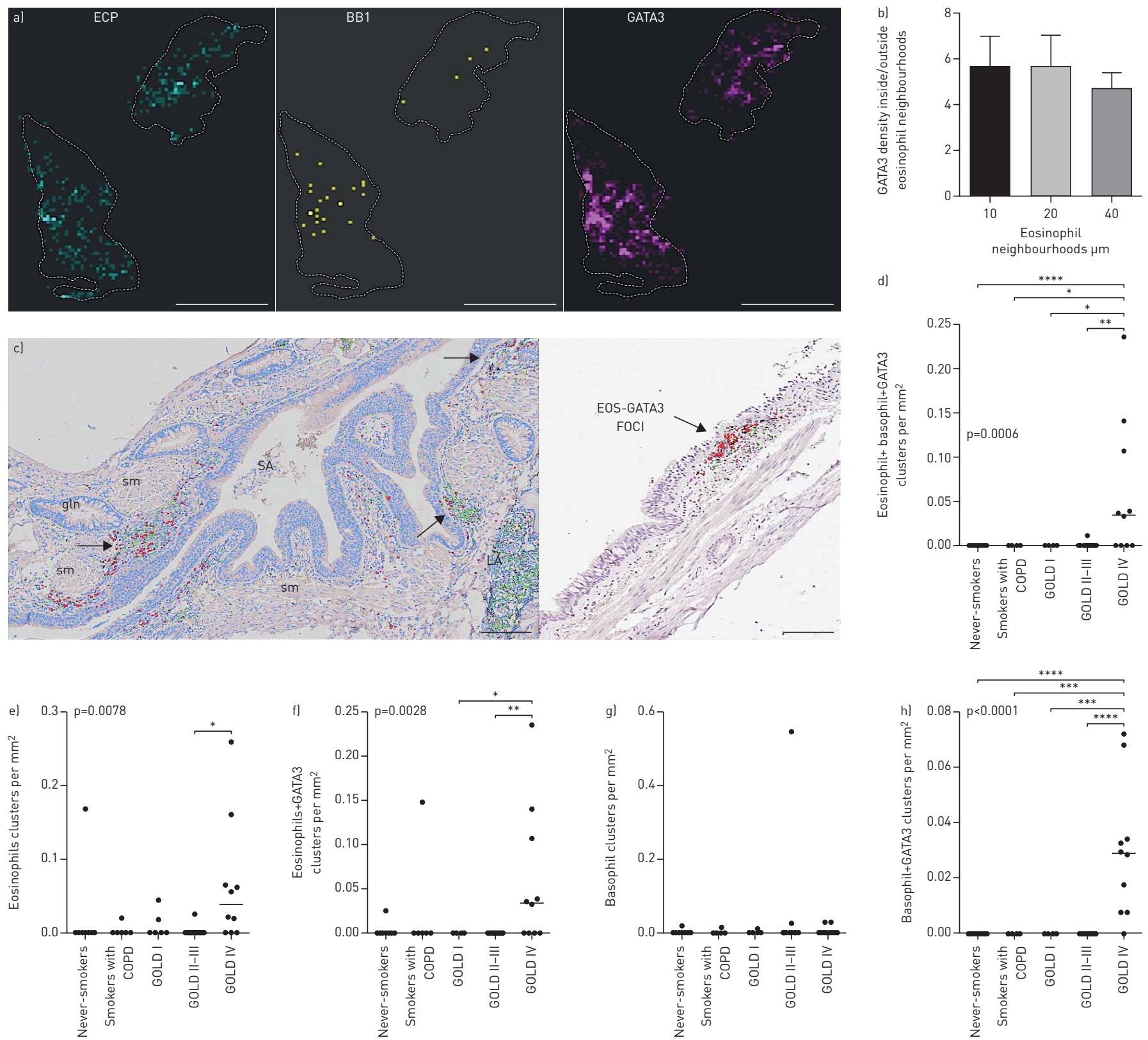

FIGURE 5 Heterogeneous spatial distribution and presence of distinct eosinophil-rich type 2 skewed microenvironments in COPD lungs. a) Spatially linked heat maps exemplifying a gross codistribution of $E G 2^{+}$eosinophils, $\mathrm{BB}^{+}$basophils and GATA3 and depicting individual $300 \times 300 \mu \mathrm{m}$ microenvironments colour-coded for cell density (black-bright represents low-high density). b) Spatial statistics analysis (see supplementary figure E1 and text for methodology details) shows the quotient of GATA3 densities inside eosinophil neighbourhoods over GATA3 densities outside eosinophil neighbourhoods. Data are shown for three levels of computer-created circular eosinophil neighbourhoods/ microenvironments, defined by a radius of 10,20 and $40 \mu \mathrm{m}$ around individual eosinophils. c) Distinct spatial foci of eosinophils (pseudo-colour-coded red after computerised image analysis) and GATA3 (green). The clustering of eosinophils was also confirmed by point pattern statistics, nearest neighbour's distance analysis, and Ripley's K point pattern analysis (supplementary material). d-h) Quantitative data on tissue density of eosinophil clusters and/or basophil clusters, with and without content of any GATA3 cells. Data are presented as patient mean clusters per $\mathrm{mm}^{2}$ lung tissue and group median values. $\mathrm{p}$-values represent overall statistical difference between patients with COPD and controls, as determined by a nonparametric Kruskal-Wallis one-way ANOVA with Dunn's multiple comparison post hoc test (mean rank of each subgroup is compared to every other subgroup). EOS: eosinophils; gln: subepithelial gland; LA: lymphoid aggregate; SA: small airway; sm: smooth muscle. Scale bars a) $1 \mathrm{~cm}$, b) $150 \mu \mathrm{m}$, c) $250 \mu \mathrm{m} .{ }^{*}: \mathrm{p}<0.05,{ }^{* *}: \mathrm{p}<0.01,{ }^{* * *}: p<0.001$.

because there was no perfect age and sex match with control patients, this result should be interpreted with caution, and it should be noted that the sample size of our study does not permit any conclusion about steroid responsiveness.

Previous studies have found eosinophilia to be a significant feature in a subset of COPD patients [6]. In the present study, a statistical increase in eosinophilia was detected only in very severe COPD. It should be 

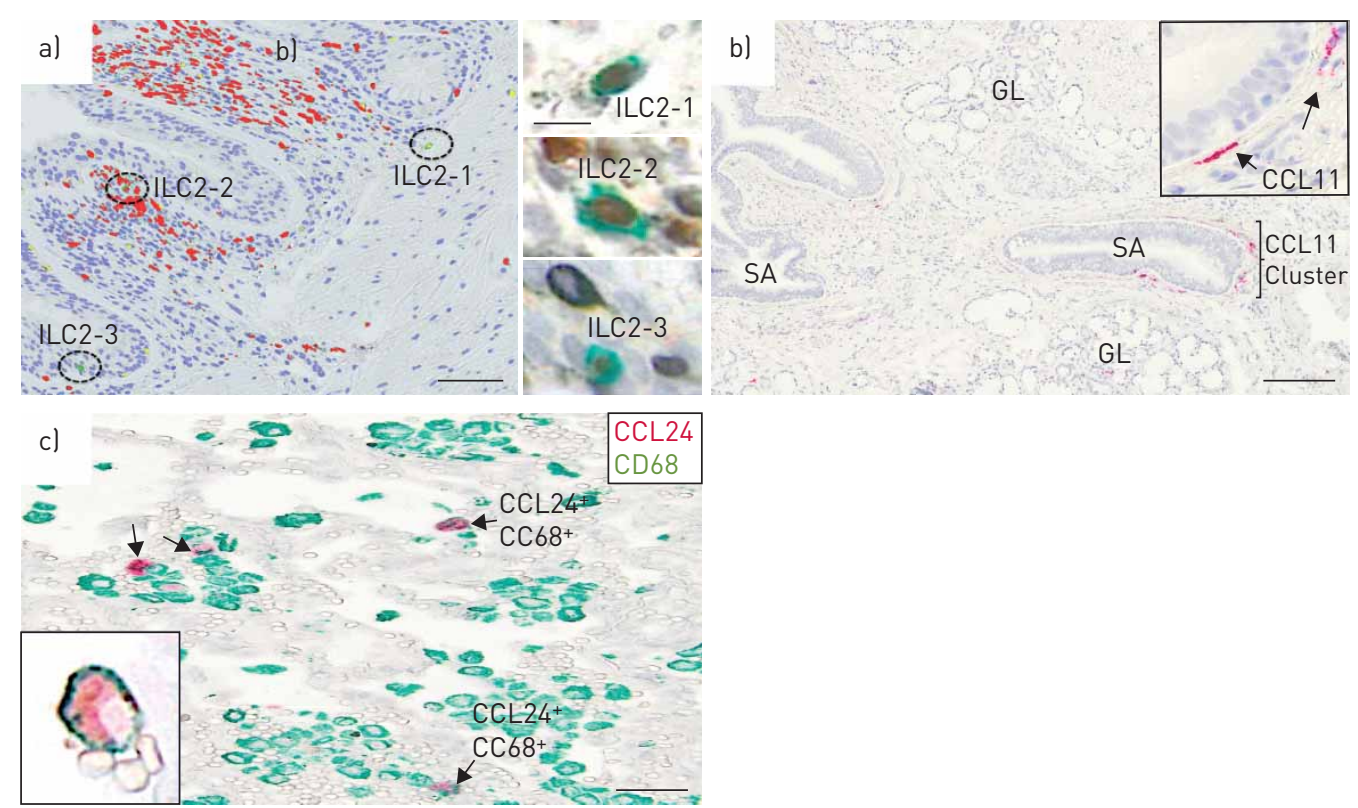

FIGURE 6 a) Example of bronchiolar eosinophil (red) foci and presence of lineage-negative GATA $3^{+} \mathrm{CD} 25^{+}$ type 2 innate lymphoid cells (ILC2) in a Global Initiative for Chronic Obstructive Lung Disease (GOLD) IV patient (green; cell nuclei in blue). Inserts depict the original micrographs of the same ILC2s (GATA3 brown; CD25 green). b) Bright-field images exemplifying focal distribution of CCL-11 (eotaxin 1) mRNA expression. CCL-11 mRNA was detected using in situ hybridisation and visualised by permanent red substrate chromogen. The low-power overview illustrates patchy clustering of $\mathrm{CCL}-11^{+}$cells, whereas greater magnification (inset in b) reveals the elongated fibroblast-like morphology of the CCL-11 ${ }^{+}$cells. c) Example of CD68-negative CCL11 (green only) cells and $\mathrm{CD} 68^{+} \mathrm{CCL} 24^{+}$(red and green) cells in a COPD-affected lung. GL: subepithelial mucus glands; SA: small airway (i.e. bronchioles). Scale bars a) $100 \mu \mathrm{m}$ (inset $10 \mu \mathrm{m}$ ), b) $200 \mu \mathrm{m}$, c) $50 \mu \mathrm{m}$.

noted that all GOLD stage IV patients had ceased smoking, whereas $\sim 40 \%$ of the milder patients were current smokers. Hence, because smoke exposure can counteract type 2 responses (which was here supported by the present mouse experiments), it cannot be excluded that ongoing smoking may contribute to the lower eosinophilia observed in milder disease. Furthermore, the present study design cannot inform to what degree transient eosinophilia occurs in exacerbating GOLD stage I-III patients. A novel study finding was the anatomically widespread eosinophil infiltration involving all major anatomical compartments in COPD-affected lungs. The results complement another study reporting that patients with COPD and greater blood eosinophil counts $\left(>250\right.$ cells $\left.\cdot \mu \mathrm{L}^{-1}\right)$ had correspondingly greater sputum and bronchoalveolar lavage eosinophil counts compared with patients with lesser blood eosinophil counts $\left(<150\right.$ cells $\left.\mu \mathrm{L}^{-1}\right)$ [28]. These patients with eosinophilic COPD also had increased eosinophils in various lung locations and greater tissue remodelling [28]. Apart from the previously identified luminal and bronchial eosinophilia in nonallergic patients with COPD $[9,29,30]$, eosinophils in COPD may exert effector functions in bronchioles, the alveolar parenchyma and ectopic lymphoid aggregates.

Another major observation was that the distribution of eosinophils displayed a marked and distinct patchiness at a microenvironmental level. This indicates that the underlying, but unidentified, cause of eosinophilia in nonallergic patients with COPD is likely to emanate from external sources that act in a highly localised fashion. It also means that the immunological responses eliciting and manifesting eosinophilia are probably also highly localised. This was supported by our finding of a clear spatial relationship between eosinophils and the surrogate type 2 marker GATA3. Expression of GATA3 is essential for type 2 cytokine production by both Th2 lymphocytes and ILC2 cells [31-33] and is targeted to combat type 2 immunity in the clinic [30]. Therefore, it was important to find that not only GATA3 ${ }^{+}$ Th2 lymphocytes but also GATA3 ${ }^{+}$ILC2 cells were identified in eosinophil-rich pockets. ILC2 cells with capacity to produce type 2 cytokines have previously been demonstrated in COPD lungs in small $(\sim 0.05 \%$ of the $\mathrm{CD} 45^{+}$cells), but probably biologically relevant numbers [34]. In agreement, our study revealed a clear dominance of Th2 cells over ILC2s in numbers, although the ILC2/Th2 ratio was only 1:6 in the epithelium lining.

Our finding of highly localised Th2 and eosinophil-rich pockets in COPD-affected lungs is conceptually novel, and an important future challenge for evaluating patients' inflammatory status. For example, blood or sputum eosinophilia indicates the presence of tissue eosinophilia, but does not exclude the possibility 

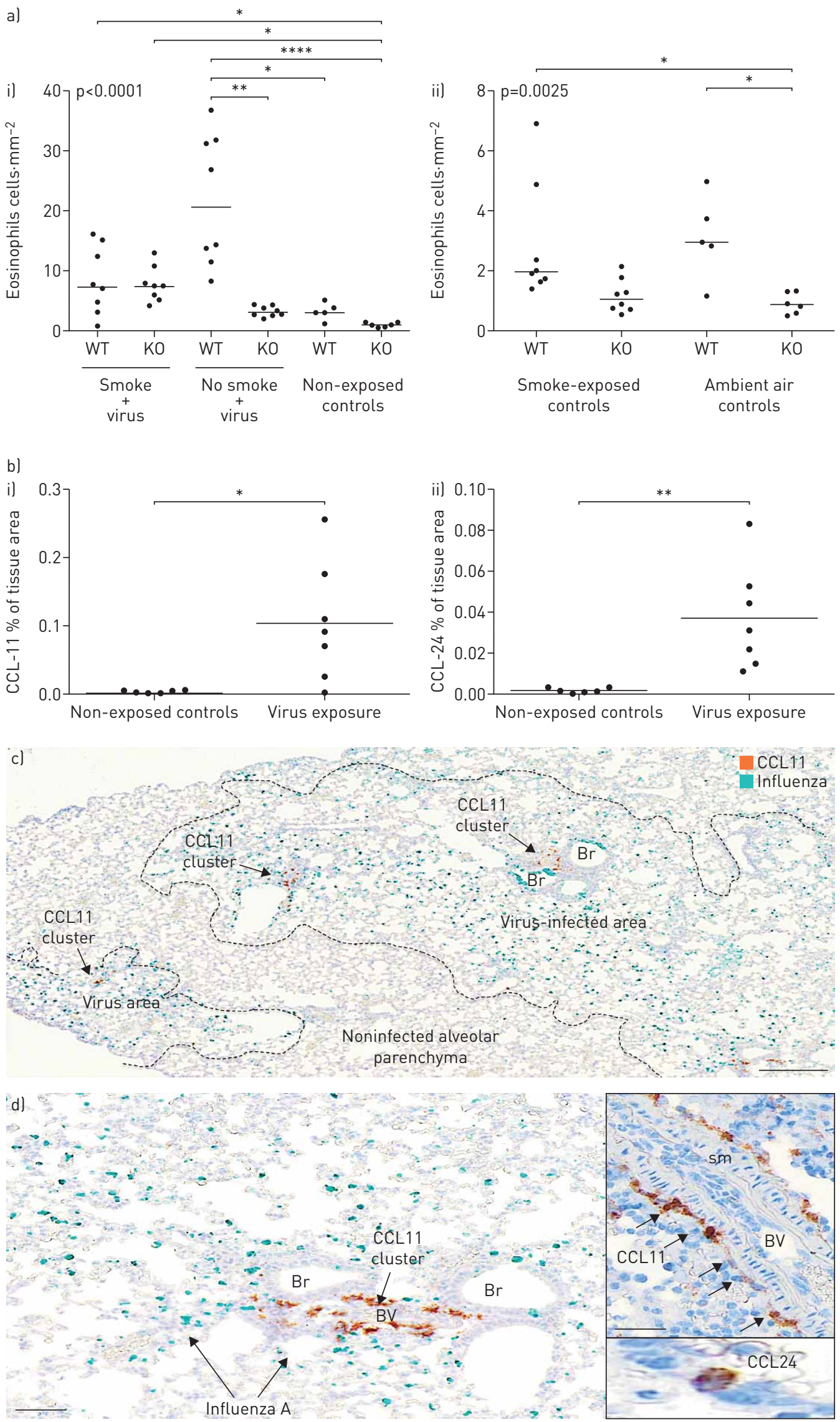
FIGURE 7 An influenza viral infection triggers a patchy eosinophilia and a highly localised induction of pro-eosinophilic chemokines. a) Infection-induced eosinophilia. Data are presented for wild-type (WT) and interleukin (IL)-33 knockout (KO) mice i) at 6 days post-influenza A infection with and without 11 days of daily tobacco smoke exposure; ii) noninfected baseline counts (no virus) of eosinophils in ambient air and tobacco smoke-exposed controls. Data are presented for WT and IL-33 KO mice. b) Mean measurements of lung tissue i) CCL11 and ii) CCL24 immunoreactivity in control and virus-infected WT mice at 6 days post-infection. $\mathrm{c}$ and d) Spatially localised presence of CCL11 in mouse lungs at 6 days post-infection. Example of typical and highly localised CCL11 clusters (brown) in virus-infected areas (virus is stained by vina green chromogen). Note the distinct CCL11 localisation around bronchial- and bronchiole-associated pulmonary blood vessels (BV). Inset in d exemplifies perivascular CCL $11^{+}$cells as well as a typical solitary CCL2 $4^{+}$alveolar cell. Br: bronchi; sm: smooth muscle. Scale bars c) $200 \mu \mathrm{m}$, d) $100 \mu \mathrm{m}$ (inset $50 \mu \mathrm{m}$ ).

that a significant portion or other lung regions will have an innate macrophage and neutrophil-rich or type 1 T-helper cell type inflammation. This represents a significant future challenge for improved personalised treatment and helps to understand the challenges of targeting type 2 mechanisms in COPD lungs.

In agreement with published studies in human and mice showing that viral infections can evoke a transient eosinophilia [35-37], this study confirms that robust eosinophilia develops after an influenza infection in mouse lungs. In our experimental model we reveal further that this eosinophil response is highly patchy, associated with a spatially localised eotaxin response and dependent on IL-33 release, as eosinophilia did not develop in IL-33 $3^{-/}$mice. In addition, in agreement with experimental myocarditis models [38], our combined ISH and IHC revealed CCL11 to be foremost expressed by fibroblasts and pericytes whereas CCL24 was localised in macrophages. Our experimental data, along with the fact that viral infections are common during COPD exacerbations [39], propose patchy localised infections as one plausible trigger of the present novel type of patchy type 2, eosinophil-rich pockets. Indeed, our data suggest that patchy eosinophilia is more common in advanced disease, during which patients develop more infections compared with earlier stages [39]. However, a limitation of our study was that patient groups were relatively small, and the evidence for an infectious cause of patchy eosinophilia remains indirect. Larger studies that involve larger cohorts and broader assessment of microbes (bacteria and viruses) are thus warranted.

In addition, this study represents the first systematic mapping of tissue-infiltrating basophils in COPD. Altogether, the basophil densities correlated with that of eosinophils. However, because basophils are virtually absent under controlled situations, the relative magnitude of increase was larger than is usually observed for many other immune cells. Interestingly, similar to observations for asthma [40], the tissue density of basophils increased with disease severity. The preferential sites of infiltration were ectopic lymphoid tissue in distal lung and conducting airways, where, for example, intraepithelial basophils in small airways displayed a dramatic increase in GOLD type IV patients. This infiltration pattern is compatible with the modern view of basophils as potent immune modulators and host defence cells [41, 42]. For example, basophils may amplify a localised type 2 response by IL- 4 secretions $[11,43]$, are activated by IL-33 and thymic stromal lymphopoietin, and may release a variety of proinflammatory cytokines in addition to histamine. In recent experimental models, basophils have been identified as having a role in emphysema development [44] and they have also been linked to the defence against COPD-relevant bacteria and viruses [41]. Basophils may thus, beside their harmful pathogenic capacity, also play a protective role. In any case, the present study suggests that basophils, which like eosinophils express IL-5R $\alpha$, should be recognised as a potentially relevant target for IL-5- and IL-5R $\alpha$-targeting therapies.

It remains to be explored to what extent eosinophils in COPD tissues undergo piecemeal degranulation, programmed cytolysis or secondary necrosis [43, 45]. Elevated free-granule protein in bronchoalveolar lavage fluid or sputum samples in asthma and COPD has frequently been viewed as a sign of active degranulation [46], but liberation of luminal granule proteins is noticeably caused by intraluminal necrotic mechanisms. Unfortunately, our samples were not suitable for electron microscopy, preventing an ultrastructural analysis of degranulation status, and the activation status of eosinophils in COPD tissues also remains to be determined.

In summary, this study identifies basophils as having a potential role in COPD and demonstrates that tissue eosinophilia in COPD is anatomically widespread but commonly confined to distinct Th2-skewed and ILC2-containing microenvironments. This feature of tissue eosinophilia is likely to have clinical implications. Furthermore, our data suggest respiratory infections as a potential trigger of patchy eosinophilia in COPD.

Acknowledgements: We thank Karin Jansner (Medetect AB, Lund, Sweden) and Britt-Marie Nilsson (Unit of Airway Inflammation, Lund University, Lund), for skilful tissue preparation and histological work. Editing support, under the direction and guidance of the authors, and manuscript submission, was provided by Debra Scates (JK Associates, Inc., 
Conshohocken, PA, USA) and Michael A. Nissen (AstraZeneca, Gaithersburg, MD, USA). This support was funded by AstraZeneca.

Conflict of interest: P. Jogdand has nothing to disclose. P. Siddhuraj has nothing to disclose. M. Mori has nothing to disclose. C. Sanden has nothing to disclose. J. Jönsson has nothing to disclose. A.F. Walls has nothing to disclose. J. Kearley is an employee of AstraZeneca (formerly MedImmune LLC) and has stock options in AstraZeneca.

A.A. Humbles was an employee of AstraZeneca (formerly MedImmune LLC) at the time these analyses were conducted.

R. Kolbeck was an employee of AstraZeneca (formerly MedImmune LLC) at the time these analyses were conducted.

L. Bjermer has nothing to disclose. P. Newbold is an employee of AstraZeneca (formerly MedImmune LLC) and has stock options in AstraZeneca. J.S. Erjefält is founder (and stock owner) of Medetect AB, who received funding from AstraZeneca for conducting parts of the present study.

Support statement: Funding for this study was provided by AstraZeneca, the Swedish Heart and Lung Foundation and the Swedish Research Council. Funding information for this article has been deposited with the Crossref Funder Registry.

\section{References}

1 Rabe KF, Hurd S, Anzueto A, et al. Global strategy for the diagnosis, management, and prevention of chronic obstructive pulmonary disease: GOLD executive summary. Am J Respir Crit Care Med 2007; 176: 532-555.

2 Hogg JC, Timens W. The pathology of chronic obstructive pulmonary disease. Annu Rev Pathol 2009; 4: 435-459.

3 Barnes PJ. Immunology of asthma and chronic obstructive pulmonary disease. Nat Rev Immunol 2008; 8: $183-192$.

4 Mori M, Andersson CK, Svedberg KA, et al. Appearance of remodelled and dendritic cell-rich alveolar-lymphoid interfaces provides a structural basis for increased alveolar antigen uptake in chronic obstructive pulmonary disease. Thorax 2013; 68: 521-531.

5 Hogg JC, Chu F, Utokaparch S, et al. The nature of small-airway obstruction in chronic obstructive pulmonary disease. N Engl J Med 2004; 350: 2645-2653.

6 George L, Brightling CE. Eosinophilic airway inflammation: role in asthma and chronic obstructive pulmonary disease. Ther Adv Chronic Dis 2016; 7: 34-51.

7 Singh D, Kolsum U, Brightling CE, et al. Eosinophilic inflammation in COPD: prevalence and clinical characteristics. Eur Respir J 2014; 44: 1697-1700.

8 Vedel-Krogh S, Nielsen SF, Lange P, et al. Blood eosinophils and exacerbations in chronic obstructive pulmonary disease. The Copenhagen General Population Study. Am J Respir Crit Care Med 2016; 193: 965-974.

9 Bafadhel M, McKenna S, Terry S, et al. Acute exacerbations of chronic obstructive pulmonary disease: identification of biologic clusters and their biomarkers. Am J Respir Crit Care Med 2011; 184: 662-671.

10 Willebrand R, Voehringer D. Regulation of eosinophil development and survival. Curr Opin Hematol 2017; 24: 9-15.

11 Wynn TA. Type 2 cytokines: mechanisms and therapeutic strategies. Nat Rev Immunol 2015; 15: 271-282.

12 Brightling CE, Bleecker ER, Panettieri RA, et al. Benralizumab for chronic obstructive pulmonary disease and sputum eosinophilia: a randomised, double-blind, placebo-controlled, phase 2a study. Lancet Respir Med 2014; 2: 891-901.

13 Pavord ID, Chanez P, Criner GJ, et al. Mepolizumab for eosinophilic chronic obstructive pulmonary disease. N Engl J Med 2017; 377: 1613-1629.

14 Sridhar S, Liu H, Pham TH, et al. Modulation of blood inflammatory markers by benralizumab in patients with eosinophilic airway diseases. Respir Res 2019; 20: 14.

15 Lacoste JY, Bousquet J, Chanez P, et al. Eosinophilic and neutrophilic inflammation in asthma, chronic bronchitis, and chronic obstructive pulmonary disease. J Allergy Clin Immunol 1993; 92: 537-548.

16 Turato G, Semenzato U, Bazzan E, et al. Blood eosinophilia neither reflects tissue eosinophils nor worsens clinical outcomes in chronic obstructive pulmonary disease. Am J Respir Crit Care Med 2018; 197: 1216-1219.

17 Walker JA, Barlow JL, McKenzie AN. Innate lymphoid cells - how did we miss them? Nat Rev Immunol 2013; 13 75-87.

18 Spits H, Cupedo T. Innate lymphoid cells: emerging insights in development, lineage relationships, and function. Annu Rev Immunol 2012; 30: 647-675.

19 Brusselle GG, Joos GF, Bracke KR. New insights into the immunology of chronic obstructive pulmonary disease. Lancet 2011; 378: 1015-1026.

20 Bal SM, Bernink JH, Nagasawa M, et al. IL-1ß, IL-4 and IL-12 control the fate of group 2 innate lymphoid cells in human airway inflammation in the lungs. Nat Immunol 2016; 17: 636-645.

21 Silver JS, Kearley J, Copenhaver AM, et al. Inflammatory triggers associated with exacerbations of COPD orchestrate plasticity of group 2 innate lymphoid cells in the lungs. Nat Immunol 2016; 17: 626-635.

22 Kearley J, Silver JS, Sanden C, et al. Cigarette smoke silences innate lymphoid cell function and facilitates an exacerbated type I interleukin-33-dependent response to infection. Immunity 2015; 42: 566-579.

23 Eltboli O, Mistry V, Barker B, et al. Relationship between blood and bronchial submucosal eosinophilia and reticular basement membrane thickening in chronic obstructive pulmonary disease. Respirology 2015; 20: 667-670.

24 Woodruff PG, van den Berge M, Boucher RC, et al. American Thoracic Society/National Heart, Lung, and Blood Institute Asthma-Chronic Obstructive Pulmonary Disease Overlap Workshop Report. Am J Respir Crit Care Med 2017; 196: 375-381.

25 Brindicci C, Ito K, Resta O, et al. Exhaled nitric oxide from lung periphery is increased in COPD. Eur Respir J 2005; 26: 52-59.

26 Bafadhel M, McKenna S, Terry S, et al. Blood eosinophils to direct corticosteroid treatment of exacerbations of chronic obstructive pulmonary disease: a randomized placebo-controlled trial. Am J Respir Crit Care Med 2012; 186: 48-55.

27 Bafadehl M, Peterson S, De Blas MA, et al. Predictors of exacerbation risk and response to budesonide in patients with chronic obstructive pulmonary disease: a post-hoc analysis of three randomised trials. Lancet Respir Med 2018; 6: 117-126. 
disease with higher blood eosinophil counts. J Allergy Clin Immunol 2017; 140: 1181-1184.

Snoeck-Stroband JB, Lapperre TS, Gosman MM, et al. Chronic bronchitis sub-phenotype within COPD inflammation in sputum and biopsies. Eur Respir J 2008; 31: 70-77.

30 Nair P, Ochkur SI, Protheroe C, et al. Eosinophil peroxidase in sputum represents a unique biomarker of airway eosinophilia. Allergy 2013; 68: 1177-1184.

31 Das J, Chen $\mathrm{CH}$, Yang L, et al. A critical role for NF- $\kappa \mathrm{B}$ in GATA3 expression and $\mathrm{T}_{\mathrm{H}} 2$ differentiation in allergic airway inflammation. Nat Immunol 2001; 2: 45-50.

32 Nakayama T, Hirahara K, Onodera A, et al. Th2 cells in health and disease. Annu Rev Immunol 2017; 35: 53-84.

33 Klein Wolterink RG, Serafini N, van Nimwegen M, et al. Essential, dose-dependent role for the transcription factor Gata3 in the development of IL- $5^{+}$and IL-13 ${ }^{+}$type 2 innate lymphoid cells. Proc Natl Acad Sci USA 2013; 110: 10240-10245.

34 De Grove KC, Provoost S, Verhamme FM, et al. Characterization and quantification of innate lymphoid cell subsets in human lung. PLoS One 2016; 11: e0145961.

35 Su YC, Townsend D, Herrero LJ, et al. Dual proinflammatory and antiviral properties of pulmonary eosinophils in respiratory syncytial virus vaccine-enhanced disease. J Virol 2015; 89: 1564-1578.

36 Samarasinghe AE, Melo RC, Duan S, et al. Eosinophils promote antiviral immunity in mice infected with influenza A virus. J Immunol 2017; 198: 3214-3226.

37 Fraenkel DJ, Bardin PG, Sanderson G, et al. Lower airways inflammation during rhinovirus colds in normal and asthmatic subjects. Am J Respir Crit Care Med 1995; 151: 879-886.

38 Diny NL, Hou X, Barin JG, et al. Macrophages and cardiac fibroblasts are the main producers of eotaxins and regulate eosinophil trafficking to the heart. Eur J Immunol 2016; 46: 2749-2760.

39 Sethi S, Mallia P, Johnston SL. New paradigms in the pathogenesis of chronic obstructive pulmonary disease II. Proc Am Thorac Soc 2009; 6: 532-534.

40 Kepley CL, McFeeley PJ, Oliver JM, et al. Immunohistochemical detection of human basophils in postmortem cases of fatal asthma. Am J Respir Crit Care Med 2001; 164: 1053-1058.

41 Karasuyama H, Yamanishi Y. Basophils have emerged as a key player in immunity. Curr Opin Immunol 2014; 31: $1-7$.

42 Wedemeyer J, Tsai M, Galli SJ. Roles of mast cells and basophils in innate and acquired immunity. Curr Opin Immunol 2000; 12: 624-631.

43 Erjefält JS, Persson CG. New aspects of degranulation and fates of airway mucosal eosinophils. Am J Respir Crit Care Med 2000; 161: 2074-2085.

44 Shibata S, Miyake K, Tateishi T, et al. Basophils trigger emphysema development in a murine model of COPD through IL-4-mediated generation of MMP-12-producing macrophages. Proc Natl Acad Sci USA 2018; 115: 13057-13062.

45 Melo RC, Weller PF. Piecemeal degranulation in human eosinophils: a distinct secretion mechanism underlying inflammatory responses. Histol Histopathol 2010; 25: 1341-1354.

46 Adelroth E, Rosenhall L, Johansson SA, et al. Inflammatory cells and eosinophilic activity in asthmatics investigated by bronchoalveolar lavage. The effects of antiasthmatic treatment with budesonide or terbutaline. Am Rev Respir Dis 1990; 142: 91-99. 